\title{
Metal-ceramic functionally graded materials - manufacturing, characterization, application
}

\author{
M. CHMIELEWSKI* and K. PIETRZAK
}

Institute of Electronic Materials Technology, 133 Wólczyńska St, 01-919 Warsaw, Poland

\begin{abstract}
Functionally graded materials (FGMs) belong to a new, continuously developing group of materials, finding application in various branches of industry. The idea of freely designing their construction profile, restricted only by the available manufacturing techniques, enables obtaining materials with composition and structure gradients having unprecedented properties. In this paper, selected results of works carried out by the authors and relating to the application of the developed metal-ceramic composites were presented in order to manufacture functionally graded materials for target purposes. Gradient structures with various construction profiles that can play different roles were produced on the basis on the following material pairs: $\mathrm{Cr}^{-} \mathrm{Al}_{2} \mathrm{O}_{3}, \mathrm{NiAl}-\mathrm{Al}_{2} \mathrm{O}_{3}$ and $\mathrm{Cu}-\mathrm{AlN}$. Manufacturing conditions, microstructure characteristics and selected properties, crucial from the point of view of future applications, were presented.
\end{abstract}

Key words: metal-ceramic functionally graded materials, manufacturing, characterization, application.

\section{Introduction}

In most cases, the term "functionally graded material" denotes material having changeable properties along one of the linear dimensions, for instance as a result of a continuous change in its chemical composition, morphology or structure. The gradient of a given feature of a given material should be understood as a systematic change in this feature observed along the direction determining the behavior of the material during its use (Fig. 1). The concept of functionally graded materials (FGMs) was developed in Japan by Niino in 1984 [1]. They were used as 'super resistant' materials in propulsion systems and fuselage coatings in spacecraft in order to decrease generated thermal stress and improve thermal resistivity [2]. At present, graded materials are more and more frequently used in power, aircraft, aerospace, electronics, automotive and chemical industry.

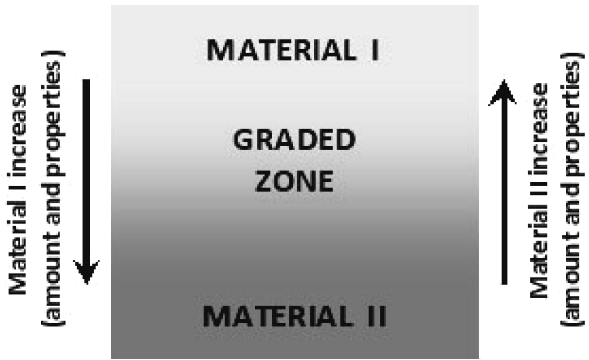

Fig. 1. Idea of functionally graded materials

Functionally graded materials are obtained using various methods, including both classical and modern techniques such as powder metallurgy, chemical vapor deposition, physical vapor deposition, plasma methods (spraying, welding), sol-gel method, liquid metal infiltration or alloy infiltration of sintered ceramic material with graded porosity [3, 4]. The selected manufacturing technique exerts influence on the structure of particular component layers (except for the chemical composition of these layers) as well as, quite importantly, on the nature of the construction profile of FGMs. The construction profile of a functionally graded material can be designed in a few ways and can be parabolic, hyperbolic or linear, with layers having different thicknesses depending on their manufacturing method. Functionally graded materials can perform different functions in complex constructions (Fig. 2).

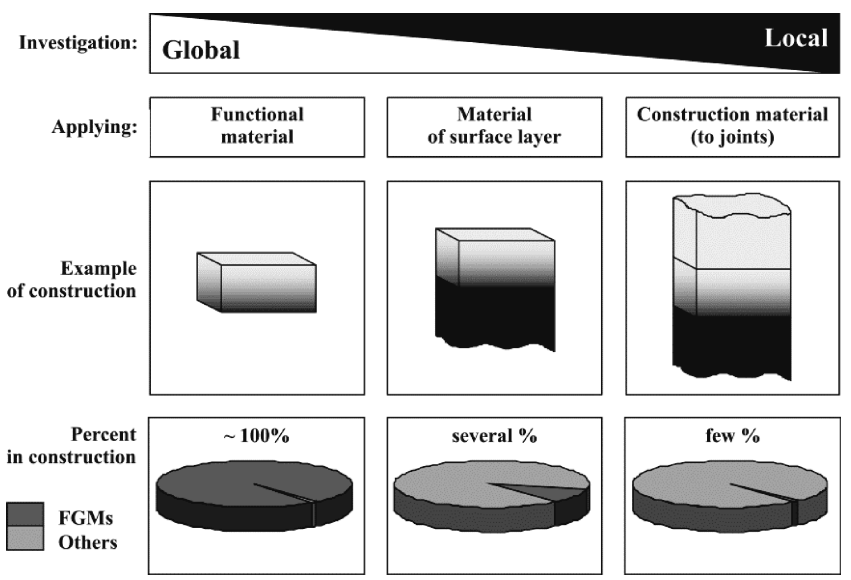

Fig. 2. Role of FGM in modern constructions after Ref. 5

As it is shown in the presented diagram, they can be either an independent system performing a given role or a top layer deposited on a substrate, thus modifying properties which are crucial from the point of view of the potential application of an element. While joining materials having considerably different properties, they can become a gradient interlayer ensuring a smooth transfer of both composition and properties from one material to another one, at the same time mini-

*e-mail: marcin.chmielewski@itme.edu.pl 
mizing the generation of significant thermal stress. There is a direct correlation between the percentage of a functionally graded material in a particular construction and its intended use; however, in each of the enumerated cases, its role is really significant. In this paper we present selected graded materials developed by the authors based on metal-ceramic composites and examples of their possible application to modern industries. The results regarding the manufacture of functionally graded materials: (i) based on $\mathrm{Cr}-(\mathrm{Re})-\mathrm{Al}_{2} \mathrm{O}_{3}$ for the power industry, (ii) based on $\mathrm{Cr}-\mathrm{Al}_{2} \mathrm{O}_{3}$ for the engineering industry, (iii) based on $\mathrm{NiAl}-\mathrm{Al}_{2} \mathrm{O}_{3}$ for the automotive industry and (iv) based on $\mathrm{AlN}-\mathrm{Cu}$ for the electronics industry, were described in detail.

\section{Results}

$\mathrm{Cr}-(\mathrm{Re})-\mathrm{Al}_{2} \mathrm{O}_{3}$ functionally graded materials for power industry - modification of the steel substrate. One of the most important aspects of developing devices for the generation of renewable energy in the process of biomass combustion is the construction of boilers, furnaces, heat exchangers and grates as well as the selection of appropriate materials from which they should be produced. Due to particularly difficult service conditions, these materials have to meet a number of often contradictory special requirements, for instance be resistant to thermal shocks, complex state of mechanical strain as well as chemical corrosion and erosion. The main reasons for the corrosion of boilers include: (i) degree of environmental aggression dependent on the composition of fuel and combustion conditions, (ii) operating temperature of an exchanger and temperature of combustion gas, which result from the construction of a boiler and (iii) inadequate properties of an exchanger material. Erosive wear of the screens of fluidized bed boilers is inextricably linked with the displacement of loose material inside a combustion chamber. The intensity of erosion is linked to the operating conditions of a boiler, properties of a transferred material and constructional solutions of a boiler. Co-combustion of biomass as well as fuel from waste is likely to increase the risk of chloride-induced corrosion of stream superheaters. Due to a usually low ash content in biomass, even if the percentage of chlorine in fuel's working substance is relatively low $(0.5 \%)$, deposits containing a significant amount of chlorides can appear on pipes. This phenomenon is caused by the deposition susceptibility of these materials, which results from high fragmentation related to their manufacturing method (vapor condensation and subsequent solidification in a form of aerosols). In order to prevent the surface of heat boilers from a corrosive influence of combustion or co-combustion of biomass, protective coatings and additives neutralizing the corrosive activity of potassium chloride and limit slagging are used. Protective coatings are an efficient method preventing chloride corrosion, which has been used in the case of waste heat boilers. Coatings based on chromium and nickel alloys are thought to be the most efficient and the most frequently used ones; however, they are really expensive [6-8]. Significantly cheaper hybrid coatings based on oxides such as aluminum [9] are a promising alter- native to metallic coatings. Composite materials which belong to this group and include metal-ceramic composites deserve great attention. $\mathrm{Cr}-\mathrm{Al}_{2} \mathrm{O}_{3}$ composites having high resistance to sudden temperature changes (the so-called thermal shocks) at $25-1300^{\circ} \mathrm{C}$, high resistance to oxidation at high temperatures (even up to $1500^{\circ} \mathrm{C}$ ), raised mechanical strength at high temperatures and high hardness $[10,11]$ can serve as an example of such materials. In addition, the properties of these materials can be enhanced by doping a metallic matrix with a low amount of rhenium [12]. Because of its unique properties, rhenium is used in industry as an additive to metal alloys which significantly improves their hardness and resistance to corrosion. Among others, these alloys find application in reaction engine blades, engine turbines and shields of special purpose vehicles [13]. There are a number of methods enabling the deposition of layers (in particular layers having a variable composition) on both metallic and non-metallic substrates available. The most important ones include: laser methods (laser spraying and pulsed laser deposition), plasma methods (plasma welding, plasma spraying, pulsed plasma deposition), magnetron sputtering, chemical vapor deposition, physical vapor deposition, etc. [14-16].

Plasma spraying can be classified as belonging to the category of thermal spraying methods in the case of which molten, semi-molten or solid particles are deposited onto a substrate. The microstructure of coatings results from their solidification and sintering. The coatings have a lamellar microstructure, which determines many of their properties [17]. A great numbers of factors should be to understood to perform the spraying process. These include the size distribution of powder, powder feed rate, powder morphology (shape, size, internal porosity), composition of working gas, spray distance, electric power input, carrier gas flow rate, etc. [18].

In this work, a "PLANCER" plasma system consisting of a PN-120 plasma-arc gun, ZN-1000 power supply and control console was used to perform plasma welding of gradient coatings. The plasma-arc gun enables the generation of plasma beam using a mixture of argon with an addition of hydrogen. A powder feeder allowing its heating was employed when performing plasma welding. The welding of coatings was carried out based on the parameters presented in Table 1.

Table 1

Plasma welding parameters for $\mathrm{Cr}-\mathrm{Al}_{2} \mathrm{O}_{3}(-\mathrm{Re})$ layers on steel substrate

\begin{tabular}{ccc}
\hline \hline & Parameter & Value \\
\hline 1. & Current intensity, A & 550 \\
\hline 2. & Voltage, $\mathrm{V}$ & 60 \\
\hline 3. & Pressure of plasma-generating argon, $\mathrm{MPa}$ & 0.7 \\
\hline 4. & Distance between substrate and gun, $\mathrm{mm}$ & 90 \\
\hline 5. & Powder price, g/min & 35 \\
\hline
\end{tabular}

In order to verify the suitability of particular composition of deposited layers, trial plasma welding on a steel substrate was performed for the following two arrangements (composition in vol.\%):

$\mathrm{I}$ - steel/ $\mathrm{Cr}-25 \% \mathrm{Al}_{2} \mathrm{O}_{3}$ layer/Cr- $40 \% \mathrm{Al}_{2} \mathrm{O}_{3}$ layer,

II - steel/ $\mathrm{Cr}-25 \% \mathrm{Al}_{2} \mathrm{O}_{3}+5 \% \mathrm{Re}$ layer/Cr- $40 \% \mathrm{Al}_{2} \mathrm{O}_{3}$ $+5 \%$ Re layer. 
Metal-ceramic functionally graded materials - manufacturing, characterization, application

The microstructure of the $\mathrm{Cr}-\mathrm{Al}_{2} \mathrm{O}_{3}$ graded structure on a steel substrate is presented in Fig. 3.

a)

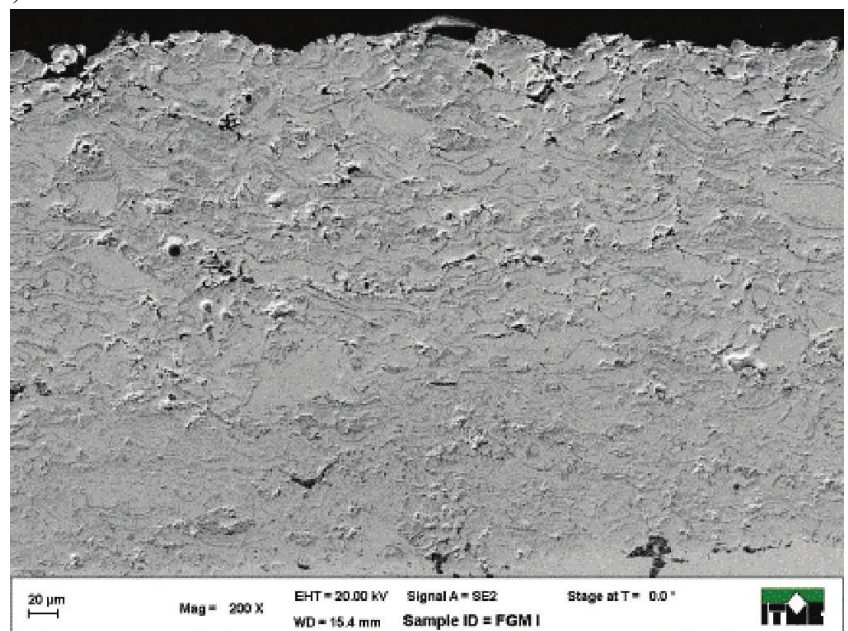

b)

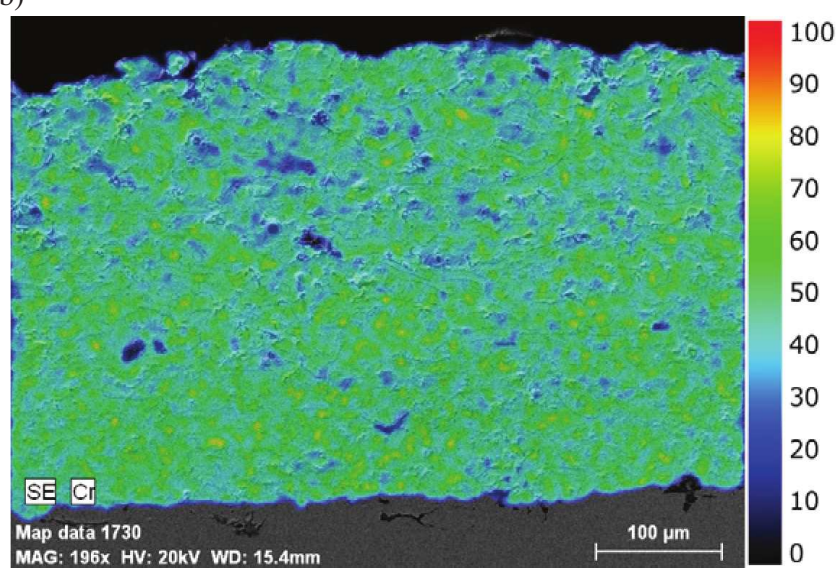

c)

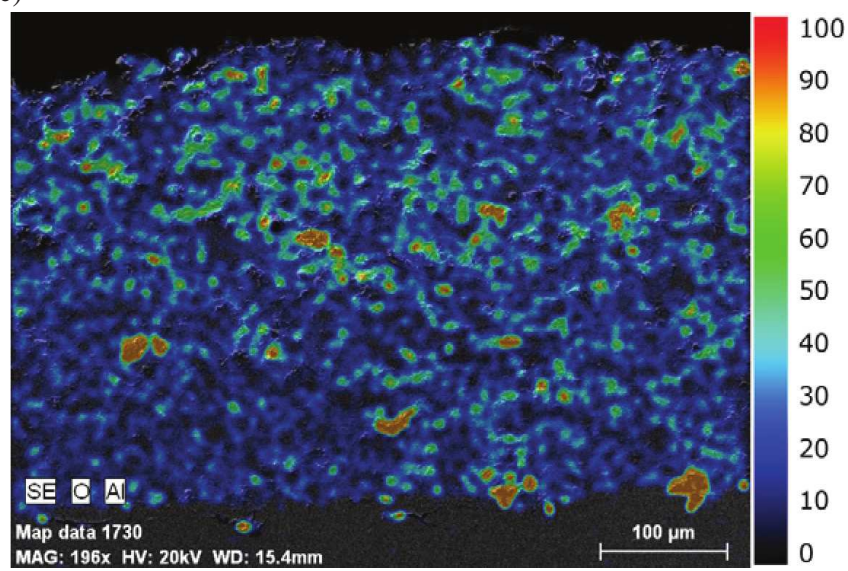

Fig. 3. SEM image of $\mathrm{Cr}-\mathrm{Al}_{2} \mathrm{O}_{3}$ graded structure sprayed on a steel substrate (a) and intensity maps of chromium (b) and aluminum/oxygen (c)
A similar analysis was performed for rhenium-containing materials (Fig. 4).

a)

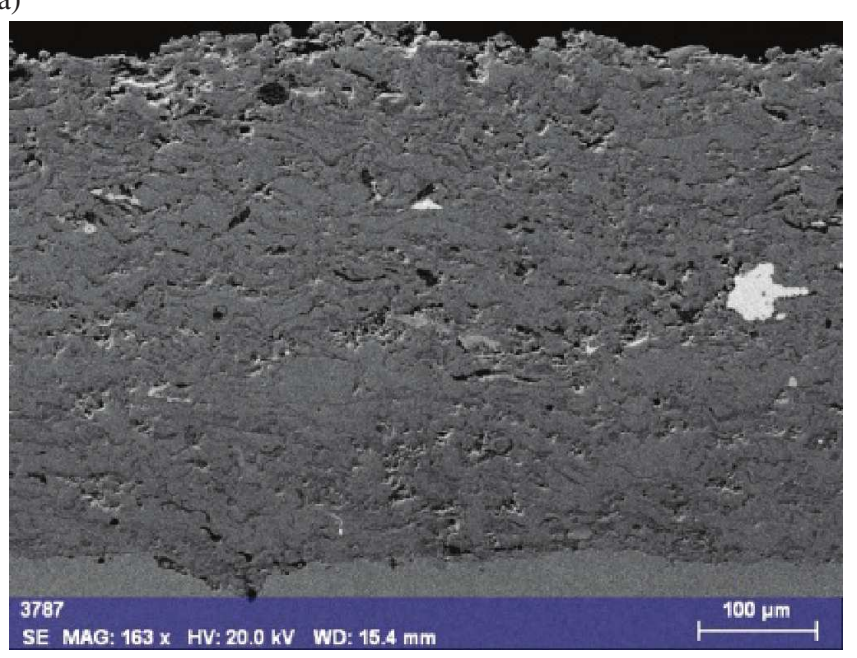

b)

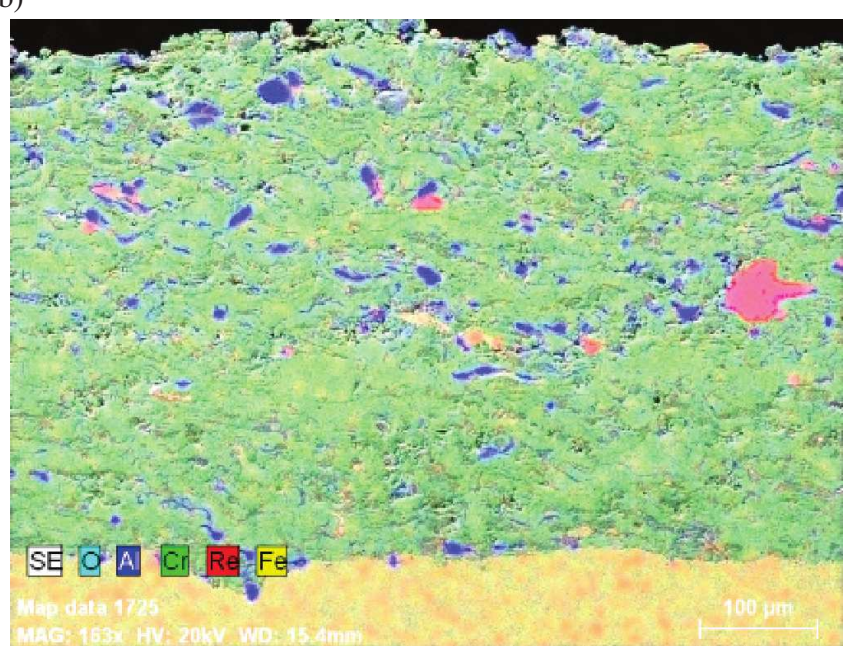

c)

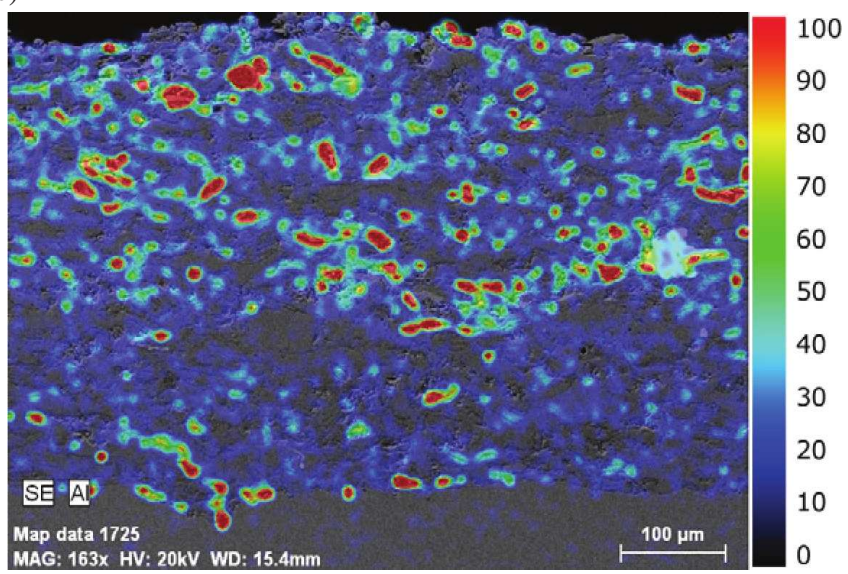

Fig. 4. SEM image of $\mathrm{Cr}-\mathrm{Re}-\mathrm{Al}_{2} \mathrm{O}_{3}$ graded structure sprayed on a steel substrate (a), maps of $\mathrm{Cr}, \mathrm{Al}, \mathrm{O}, \mathrm{Re}, \mathrm{Fe}$ (b) and aluminum intensity (c) 


\section{Chmielewski and K. Pietrzak}

The microstructural analysis revealed some porosity in thermally sprayed layers. Its degree was independent from the chemical composition of a material and the obtained values (measured by the Clemex television analysis system) were oscillating between 2 and 4\%. When looking at the substrate/FGM boundary, it was found that there is good adhesion between layers. The ceramic phase intensity was raising from the substrate to the outer surface of FGM. Rhenium was present in the structure as separate inclusions. XRD analyses did not reveal any reactions between the components of a composite layer. The surface roughness was typical of a thermal spraying process.

The described graded structure can be used in systems directly exposed to severe exploitation conditions, e.g. elevated temperature or corrosion atmosphere, just like in the case of combustion fluidal boilers (CFB) in power plants. Cr- $\mathrm{Re}-\mathrm{Al}_{2} \mathrm{O}_{3}$ composite materials have very high oxidation resistance at elevated temperatures. In oxidizing atmosphere chromium forms chromium oxide $\left(\mathrm{Cr}_{2} \mathrm{O}_{3}\right)$ which is wellmatched to $\mathrm{Al}_{2} \mathrm{O}_{3}$ ceramics. Chromium oxide obtained on the surface of a composite layer protects the structure and the entire material from oxidation [6].

The possible advantages of using the presented functionally graded material are presented in Table 2 and Fig. 5. The study of hardness enabled obtaining significantly larger composite surface when compared with that of a steel substrate.

Table 2

Hardness results for FGM systems

\begin{tabular}{lccc}
\hline \hline \multirow{2}{*}{ Material's system } & \multicolumn{3}{c}{ Hardness $\mathrm{HV}_{10}[\mathrm{GPa}]$} \\
\cline { 4 - 5 } & steel & layer 1 & layer2 \\
\hline steel/Cr- $25 \mathrm{Al}_{2} \mathrm{O}_{3} / \mathrm{Cr}-40 \mathrm{Al}_{2} \mathrm{O}_{3}$ & 0.9 & 2.6 & 2.9 \\
\cline { 4 - 5 } steel/Cr- $25 \mathrm{Al}_{2} \mathrm{O}_{3}+5 \mathrm{Re} / \mathrm{Cr}-40 \mathrm{Al}_{2} \mathrm{O}_{3}+5 \mathrm{Re}$ & & 2.8 & 3.2 \\
\hline
\end{tabular}

Another likewise important feature, especially if the materials in question are expected to work together on the surface, is their abrasive wear resistance. The performed tribological tests in a ball-plane arrangement proved a significant increase in the abrasive wear resistance of composite layers when compared to an uncovered steel substrate. Figure 5 presents exemplary wear profiles. Based on the experiments carried out in this work, it can be concluded that the wear resistance of composite materials is far better when the content of aluminum oxide is raised. At the same time, it was found that a minor addition of rhenium can be beneficial and result in both material's strengthening and improvement of its abrasive wear resistance.

Using surface modification methods in the manufacture of composition gradient materials offers excellent potential for designing new solutions with target properties and in addition due to a prolonged life-time has a positive impact on the overall cost of the construction.
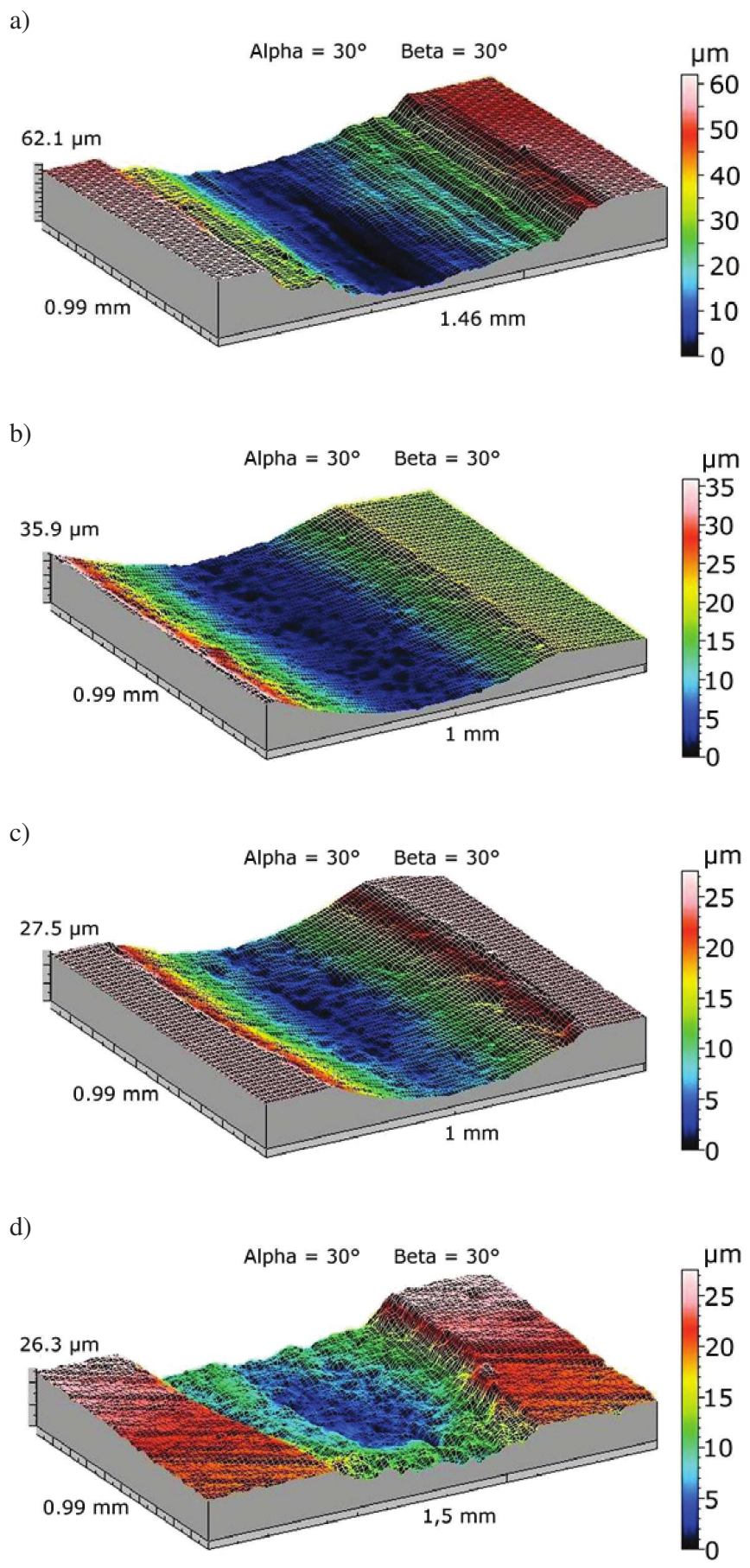

e)

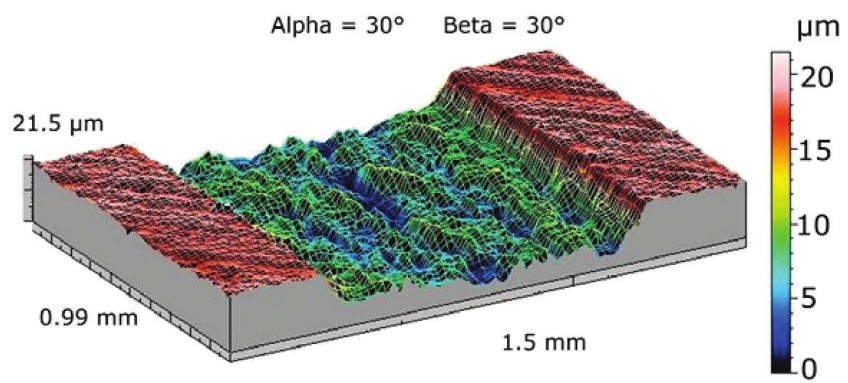

Fig. 5. 3D wear profiles of: a) uncoated steel, b) $\mathrm{Cr}-25 \mathrm{Al}_{2} \mathrm{O}_{3}$, c) $\mathrm{Cr}-$ $40 \mathrm{Al}_{2} \mathrm{O}_{3}$, d) $\mathrm{Cr}-25 \mathrm{Al}_{2} \mathrm{O}_{3}+5 \mathrm{Re}$, e) $\mathrm{Cr}-40 \mathrm{Al}_{2} \mathrm{O}_{3}+5 \mathrm{Re}$ 
$\mathrm{Cr}-\mathrm{Al}_{2} \mathrm{O}_{3}$ functionally graded materials as an interlayer for joining ceramics to steel. Modern constructions require durable joining of advanced ceramics and metal alloys having very complex shapes and composed of a great number of elements. Due to different thermal and mechanical properties of ceramic materials and metals, high internal stress is generated in bonded elements during the joining process and service load (e.g. thermal or mechanical) [19, 20]. This stress exerts influence on both the performance and life-time of ceramics-metal joints. It is likely to cause or lead to the development of cracks in ceramics, plastic deformations, accompanied by the formation or growth of intergranular voids either in metal or an interlayer, which results in decohesion. The development of ceramics bonded to metals is predominantly linked with the introduction of new ceramic materials and use of ceramic-metal joints operating under more and more harsh conditions. This applies mainly to ceramics-metal joints working at high and variable temperatures (coatings of nozzles in torches, coatings of blades in turbines etc.) or in chemically aggressive environment (chemical devices, elements of chambers for waste utilization).

When there is a need for joining corundum ceramics and high-chromium steel, using a graded material based on $\mathrm{Cr}$ $\mathrm{Al}_{2} \mathrm{O}_{3}$ composites as a separator can prove to be an effective solution [21]. Due to significant differences between their thermal and mechanical properties it is impossible to join these materials directly and durably as a result of high tensile stress in a ceramic element [22, 23]. An exact numerical analysis of internal tensile stress performed using the finite element method was described in detail in [24, 25]. It was carried out for the following three types of ceramics-steel joints: (i) direct joints, (ii) joints obtained using a $\mathrm{Cr}-\mathrm{Al}_{2} \mathrm{O}_{3}$ three-layer graded material, (iii) joints obtained using a $\mathrm{Cr}-\mathrm{Al}_{2} \mathrm{O}_{3}$ seven-layer graded material. In both cases the total thickness of a graded layer was $3 \mathrm{~mm}$.

Based on the results of the numerical analysis of internal stress in a directly-welded model of an $\mathrm{Al}_{2} \mathrm{O}_{3}$-high-chromium steel joint, stress concentration $\sigma_{\max }$ in ceramics was found to be around $550 \mathrm{MPa}$ (Fig. 6), which could have led to cracking of a ceramic element of the joint.

An application of a three-layer gradient material enabled lowering the maximum internal stress $\sigma_{\max }$ within the area of ceramics where its concentration is the highest to around $260 \mathrm{MPa}$, which means a drop of more than $50 \%$ when compared with stress in a direct joint. Adding four new layers to the graded material did not result in a sharp decrease of internal stress in the analyzed joint. When compared to the joint with a graded interlayer, composed of three $\mathrm{Al}_{2} \mathrm{O}_{3}-\mathrm{Cr}$ composite layers, the determined internal stress $\sigma_{\max }$ was only about $10 \%$ lower and equaled $236 \mathrm{MPa}$. In both cases stress was quite evenly distributed over the entire graded wafer.

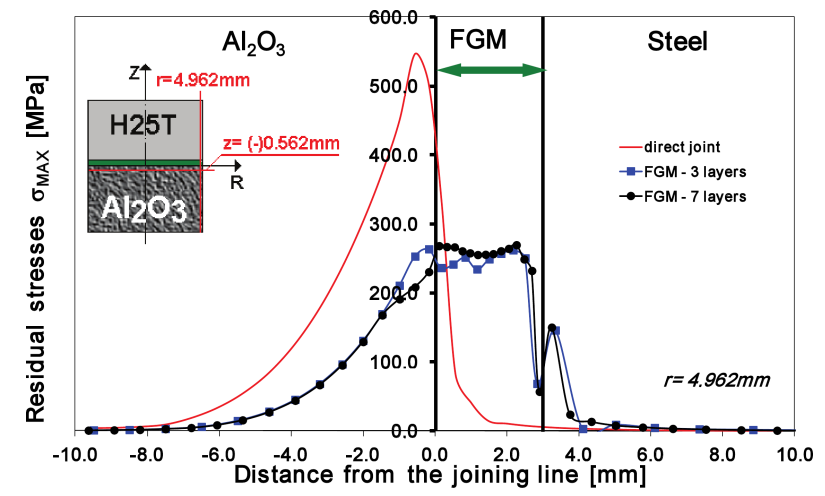

Fig. 6. Main stress distribution $\sigma_{\max }$ along the axis of ceramics-steel joint for different configurations

In order to verify the obtained results, technological trials including joining of corundum ceramics and steel were performed. Trials aimed at directly joining ceramics and steel using diffusion welding were carried out $\left(T=900^{\circ} \mathrm{C}\right.$, $t=30 \mathrm{~min}, p=30 \mathrm{MPa}$, vacuum $1 \times 10^{-6} \mathrm{~Pa}$ ). When using the graded material, this was a two-stage procedure. $\mathrm{Cr}-\mathrm{Al}_{2} \mathrm{O}_{3}$ layers were first sintered on a ceramic substrate $\left(T=1400^{\circ} \mathrm{C}\right.$, $t=30 \mathrm{~min}, p=30 \mathrm{MPa}$, argon) and subsequently steel was joined to this arrangement.

Joining alumina ceramics and steel directly together did not bring about satisfactory results. Soon after having finished the joining process, the joints were damaged as their ceramic element cracked. The cracking of the ceramic element occurred close to the dividing surface of the ceramics-steel joint. It confirms a considerable concentration of the tensile residual stresses in this particular bonding area and their high level, far exceeding the strength of alumina ceramics.

The application of a $\mathrm{Cr}-\mathrm{Al}_{2} \mathrm{O}_{3}$ gradient material as an interlayer in the joint allowed obtaining a well-bonded ceramicssteel joint of sufficient strength (Fig. 7).

As shown in the figure, a durable bonding was obtained between ceramics and steel and no defects were observed at the boundaries of the joined materials. The transition between particular layers of the graded material was smooth and had good cohesion.

The value of residual stresses $\left(\sigma_{\max }\right)$ calculated for the $3 \mathrm{~mm}$-thick gradient material was about $260 \mathrm{MPa}$, which only slightly exceeds the ceramic strength. Probably, the real level of residual stresses in the alumina/FGM/steel joint is much lower than the calculated value. It may stem from a too rough estimation method of the properties of $\mathrm{Cr}-\mathrm{Al}_{2} \mathrm{O}_{3}$ composites employed in the numerical analysis (the rule of mixture).

The application potential of the presented solution is confirmed by a great number of papers, including [26-28], describing exemplary uses of a graded interlayer for joining materials having significantly different properties. 
M. Chmielewski and K. Pietrzak

$\mathrm{Al}_{2} \mathrm{O}_{3} / \mathrm{L} 1$
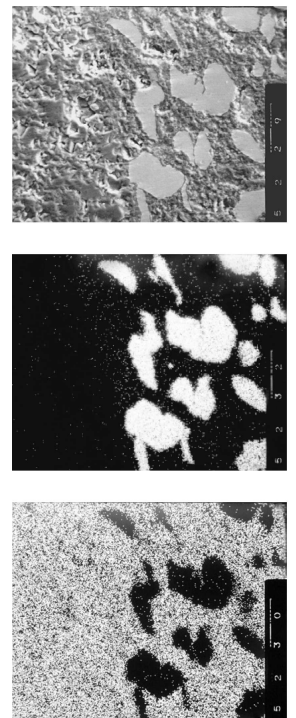

L1/L2
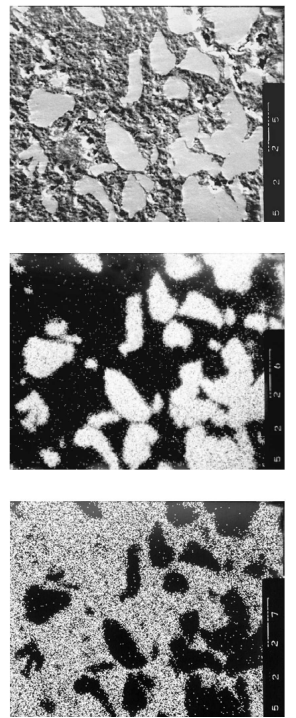

$\mathrm{L} 2 / \mathrm{L} 3$
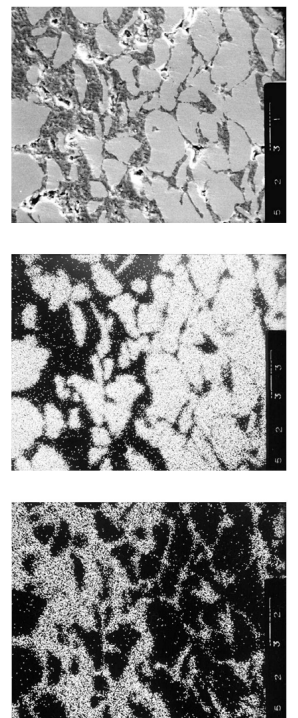

L3/steel
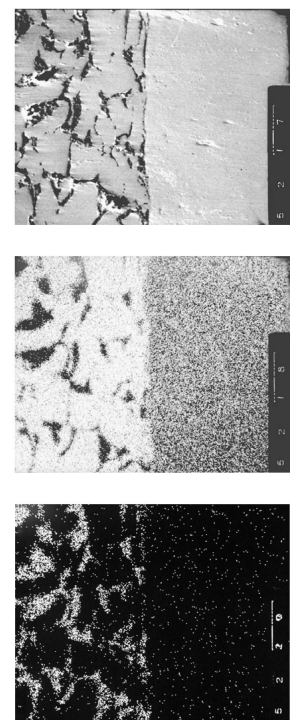

Fig. 7. Microstructure and surface distribution of elements in alumina/FGM/steel joint: $\mathrm{L} 1-75 \mathrm{Al}_{2} \mathrm{O}_{3} / 25 \mathrm{Cr}, \mathrm{L} 2-50 \mathrm{Al}{ }_{2} \mathrm{O}_{3} / 50 \mathrm{Cr}, \mathrm{L} 3-$ $25 \mathrm{Al}_{2} \mathrm{O}_{3} / 75 \mathrm{Cr}$

$\mathrm{NiAl}-\mathrm{Al}_{2} \mathrm{O}_{3}$ functionally graded materials for automotive industry - valve application. Gasoline combustion engines make use of intake and exhaust steel valves (forged, machined and coated for wear protection, Fig. 8) driven by a cam system. Exhaust valves are subjected to high thermal and mechanical alternating stresses and chemical corrosion [29]. The main disadvantage of steel valves is their weight causing higher inertia, higher friction and power dissipation, which leads to higher $\mathrm{CO}_{2}$ emission. Conventional valve train materials reach their limits when it comes to the use of alternative fuels like ethanol, hydrogen or compressed natural gas (CNG) (e.g. ethanol is very corrosive, while hydrogen and $\mathrm{CNG}$ are dry gases). This leads to an increased wear.

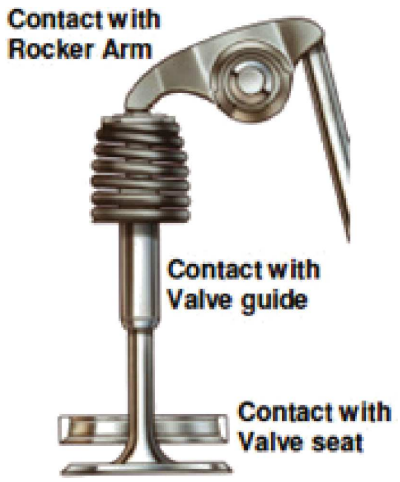

Fig. 8. Scheme of cooperating valve elements after Ref. 29

Intermetallic compounds are the materials that can meet the set requirements. Intermetallic phases of the Ni-Al type belong to a group of modern constructional materials with low density and advantageous properties. They have high melting temperature, good resistance to oxidation at high temperatures (up to about $1200^{\circ} \mathrm{C}$ ), high value of Young's modulus (stable when increasing temperature), high mechanical, fatigue, tensile and compressive strengths (also at high temperatures), and good frictional wear resistance [30-32].

Nevertheless, there are a few drawbacks to intermetallic compounds. For instance, at room temperature they are brittle and thus difficult to machine, whereas at high temperatures they are susceptible to creep. These disadvantageous properties limit their applicability but can be improved by modifying the composition of the compound or by subjecting it to appropriate plastic and/or heat treatments.

It is also possible to modify the composition of intermetallic compounds by adding a ceramic phase, which results in an improvement of a variety of their properties.

Such materials, especially in the form of a gradient, could be used as valve elements. A cylindrical part of a valve (the so-called tip) cooperating with a valve arm, exposed to high temperatures in corrosive environment and abrasive wear, is a particularly important element. That is why, it should have high mechanical strength at elevated temperatures, high hardness and impact resistance as well as high resistance to abrasive wear. Above all, the manufacture of a graded material based on the $\mathrm{NiAl}$ intermetallic phase should prolong the life time of valves.

The materials used in the performed experiments were nickel aluminide powder (Goodfellow, purity 99.9\%, average grain size $4 \mu \mathrm{m}$ ) and aluminum oxide powder (NewMet Koch, purity $99.9 \%$, average grain size $<1 \mu \mathrm{m}$ ). The proposed composition of the graded material included three composite layers sintered on a $\mathrm{NiAl}$ substrate. The following composition was prepared: $\mathrm{NiAl}+5 \% \mathrm{Al}_{2} \mathrm{O}_{3}, \mathrm{NiAl}+7.5 \% \mathrm{Al}_{2} \mathrm{O}_{3}$ and $\mathrm{NiAl}+10 \% \mathrm{Al}_{2} \mathrm{O}_{3}$ (in vol.\%). The powders were mixed in a Pulverisette 6 planetary mill (with a $250 \mathrm{ml}$ container) in an air atmosphere. The final densification process was conducted using the hot-pressing method in an argon protective atmosphere. The sintering process conditions were as follows: 
sintering temperature $1400^{\circ} \mathrm{C}$, sintering time $30 \mathrm{~min}$, pressure $30 \mathrm{MPa}$.

The presented production procedure of the powder mixtures and FGM components is described in detail in Ref. [33]. A design of the tip of the valve and the obtained FGM are shown in Fig. 9. Figure 10 shows the microstructure of the obtained FGM.

a)

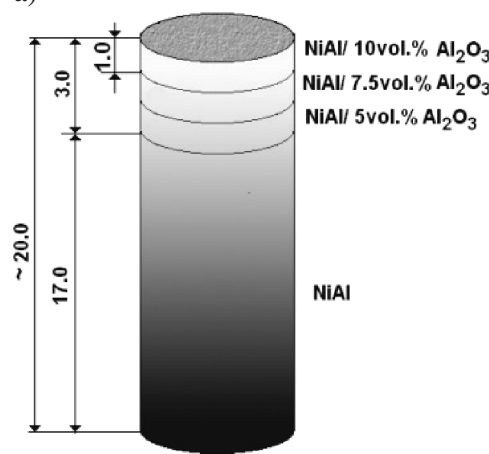

Fig. 9. Scheme of graded material to be used as valve element (a) and sample after sintering (b)

a)

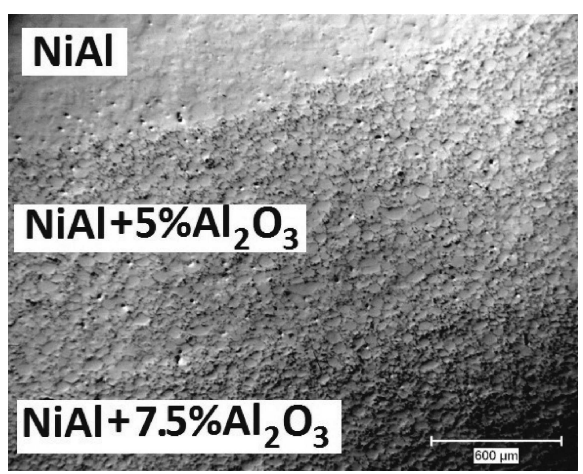

b)

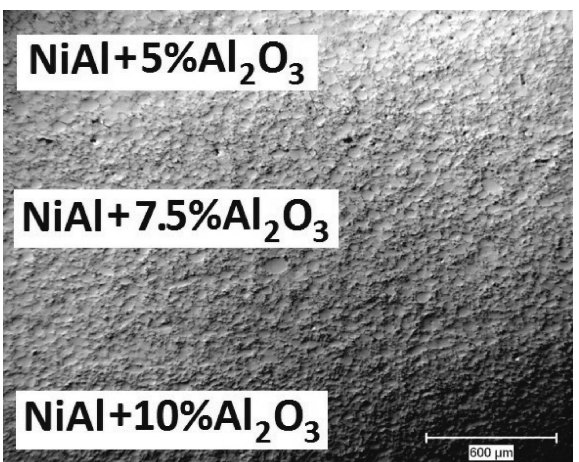

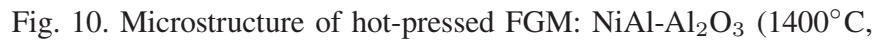
$30 \mathrm{~min}, 30 \mathrm{MPa}$ )

The obtained graded materials had homogeneous and compact structure and the ceramic phase was relatively uniformly distributed over the entire cross-section of the sample. There is a good bonding between each component of the FGM.

Selected properties of materials composing the graded material were presented in Table 3 . It can be seen that a slight addition of the ceramic phase leads to a considerable improvement of strength parameters of composites. Increased bending strength and fracture toughness is a result of changing of the fracture mode from intergranular to transgranular [34]. In Ref. [35] the author indicates plastic deformation as an additional factor influencing the toughening process. However, since the $\mathrm{NiAl}-\mathrm{Al}_{2} \mathrm{O}_{3}$ interface is weak, the crack propagates mainly through the interface, just like in the case of the CookGordon mechanism [36]. The toughening effect is predominantly caused by crack deflection and/or crack bridging.

Table 3

Properties of components of graded materials

\begin{tabular}{cccccc}
\hline \hline $\begin{array}{c}\text { Material } \\
{[\text { vol.\%] }}\end{array}$ & $\begin{array}{c}\text { Bending } \\
\text { strength } \\
{[\mathrm{MPa}]}\end{array}$ & $\begin{array}{c}K_{I C} \\
{\left[\mathrm{MPa} \cdot \mathrm{m}^{1 / 2}\right]}\end{array}$ & $\begin{array}{c}\text { Young's } \\
\text { Moduls } \\
{[\mathrm{GPa}]}\end{array}$ & $\begin{array}{c}\text { Poisson's } \\
\text { ratio }\end{array}$ & $\begin{array}{c}\text { Hardness } \\
\mathrm{HV} \\
{[\mathrm{GPa}]}\end{array}$ \\
\hline $\mathrm{NiAl}$ & $345.6 \pm 53.8$ & $7.2 \pm 0.4$ & 188 & - & 3.08 \\
\hline $\mathrm{NiAl} / 5 \% \mathrm{Al}_{2} \mathrm{O}_{3}$ & $511.8 \pm 49.8$ & $7.3 \pm 0.6$ & 190.3 & 0.303 & 3.20 \\
\hline $\mathrm{NiAl} / 7.5 \% \mathrm{Al}_{2} \mathrm{O}_{3}$ & $536.6 \pm 43.8$ & $8.3 \pm 0.4$ & 194.3 & 0.301 & 3.25 \\
\hline $\mathrm{NiAl} / 10 \% \mathrm{Al}_{2} \mathrm{O}_{3}$ & $555.4 \pm 28.7$ & $8.6 \pm 0.6$ & 197.1 & 0.3 & 3.30 \\
\hline
\end{tabular}

Cu-AIN functionally graded materials for electronics industry - heat dissipation elements. Dissipation of heat generated during the operation of high-power electronic elements (e.g. diodes, thyristors and lasers) is crucial from the point of view of their efficiency. Good cooling conditions can be guaranteed for instance by using materials with very high thermal conductivity and designing the heat dissipation system in an accurate manner. $\mathrm{Cu}-\mathrm{C}$ (carbon in a form of diamond or graphene [37, 38]), $\mathrm{Cu}-\mathrm{SiC}$ [39], $\mathrm{Cu}-\mathrm{AlN}$ [40] and $\mathrm{Cu}-\mathrm{Al}_{2} \mathrm{O}_{3}$ [41] belong to materials most often suggested for this purpose. The aluminum nitride-copper material pair fulfills the required criterion. Aluminum nitride is particularly interesting for electronics due to its high thermal conductivity, satisfactory mechanical and electrical properties as well as low coefficient of thermal expansion $\left(4.0 \times 10^{-6} 1 / \mathrm{K}\right)$, the value of which is close to that of silicon $\left(2.7 \times 10^{-6} 1 / \mathrm{K}\right)$, thus preventing the generation of high internal stress. This is extremely important due to faults in electronic arrangements related to the mismatch between coefficients of thermal expansion of a substrate and a semiconducting element. Thermal conductivity of polycrystalline aluminum nitride mentioned in the literature is not as high as in the case of an AlN monocrystal ( $319 \mathrm{~W} / \mathrm{mK}$ for a monocrystal and a bit less than $200 \mathrm{~W} / \mathrm{mK}$ for a polycrystal). The transport properties of copper (heat or current) are mainly dependent on its purity. The thermal conductivity value for copper oscillates around $400 \mathrm{~W} / \mathrm{mK}$. Nevertheless, the use of pure copper in electronics is limited due to its insufficient mechanical properties, especially at elevated temperatures. Moreover, a high value of the thermal expansion coefficient in the case of copper $\left(16.5 \times 10^{-6} 1 / \mathrm{K}\right)$ is likely to generate considerable internal stress and thermal dilatation when exposing copper elements to significant thermal changes. That is why, designed and constructed arrangements should have both high thermal conductivity and linear expansion coefficient which is significantly lower than in the case of copper. 


\section{Chmielewski and K. Pietrzak}

The performed author's works, described in detail in [42], focused on $\mathrm{Cu}-\mathrm{AlN}$ composite materials with AlN volume fractions varying from 10 to $40 \%$, which were prepared by a powder metallurgy technique. The powder mixtures were obtained in a mechanical mixing process using a planetary ball mill (Pulverisette 6, Fritsch) with tungsten carbide balls $(\varnothing 10 \mathrm{~mm})$. The mixing process was conducted in a nitrogen atmosphere with the rotational speed of $200 \mathrm{rpm}$ and the time of mixing was $4 \mathrm{~h}$. Ball-to-powder ratio (BPR) was approximately 5:1. The composite powders were consolidated using a hot-pressing method in vacuum $\left(10^{-3} \mathrm{Tr}\right)$ at $600^{\circ} \mathrm{C}$ and the pressure of $415 \mathrm{MPa}$ for $30 \mathrm{~min}$.

In order to obtain material that would ensure proper diffusion of heat flux, having high thermal conductivity and thermal expansion coefficient lower than in the case of copper based on the developed composite, the use of a four-layer graded material sintered on a copper substrate composed of the following wafers was suggested: $\mathrm{Cu} / 90 \mathrm{Cu}-10 \mathrm{AlN} / 80 \mathrm{Cu}-$ $20 \mathrm{AlN} / 70 \mathrm{Cu}-30 \mathrm{AlN} / 60 \mathrm{Cu}-40 \mathrm{AlN}$ (\% vol.), thickness of particular layers: $1.2 \mathrm{~mm}$. An image of the produced structure is presented in Fig. 11.

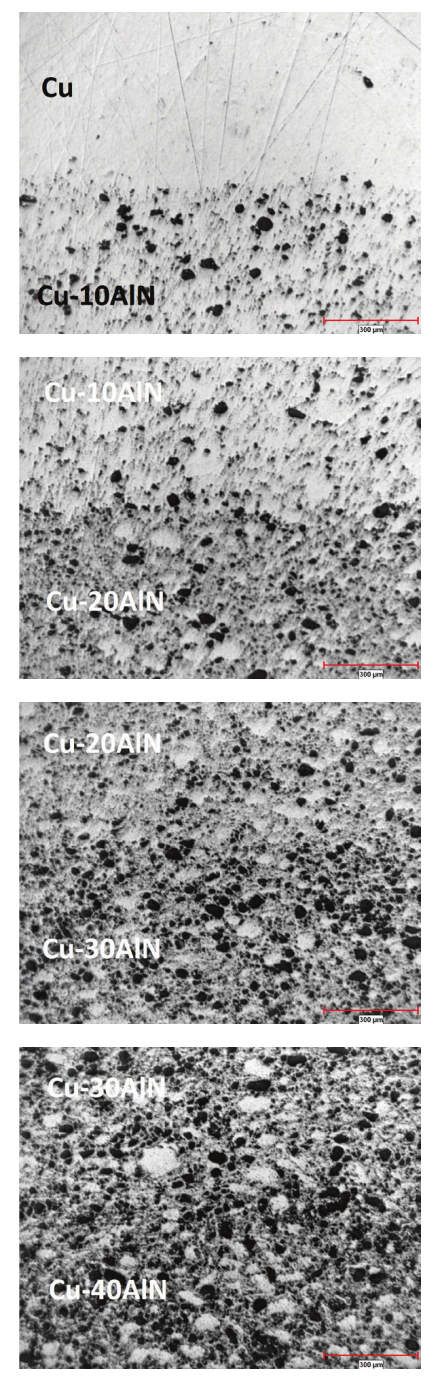

Fig. 11. Image of $\mathrm{Cu}-\mathrm{AlN}$ graded material obtained using optical microscopy
As can be seen in the presented pictures, the structure of the obtained material is compact, without visible structural defects. Slight porosity was observed mainly in the ceramics region and increased when raising the share of the ceramic phase in the graded material. These observations were confirmed by density measurements of the constituent layers of the graded material (Table 4).

Table 4

Densities of hot-pressed $\mathrm{Cu}-\mathrm{AlN}$ composites

\begin{tabular}{cccc}
\hline \hline $\begin{array}{c}\text { Chemical } \\
\text { composition } \\
{[\text { vol.\%] }}\end{array}$ & $\begin{array}{c}\text { Theoretical } \\
\text { density } \\
{\left[\mathrm{g} / \mathrm{cm}^{3}\right]}\end{array}$ & $\begin{array}{c}\text { Measured } \\
\text { density } \\
{\left[\mathrm{g} / \mathrm{cm}^{3}\right]}\end{array}$ & $\begin{array}{c}\text { Relative } \\
\text { density } \\
{[\%]}\end{array}$ \\
\hline $90 \mathrm{Cu}-10 \mathrm{AlN}$ & 8.38 & 8.27 & 98.6 \\
\hline $80 \mathrm{Cu}-20 \mathrm{AlN}$ & 7.81 & 7.69 & 98.4 \\
\hline $70 \mathrm{Cu}-30 \mathrm{AlN}$ & 7.23 & 7.08 & 97.9 \\
\hline $60 \mathrm{Cu}-40 \mathrm{AlN}$ & 6.66 & 6.45 & 96.9 \\
\hline
\end{tabular}

The thermal expansion coefficient was measured using a vertical direct dilatometer. The samples were heated up to the temperature of $600^{\circ} \mathrm{C}$ in a protective argon atmosphere at a rate of $5^{\circ} \mathrm{C} / \mathrm{min}$, maintained at this temperature for $5 \mathrm{~min}$ and, then, cooled down in an oven at an average rate of 2 to $3^{\circ} \mathrm{C} / \mathrm{min}$. The thermal diffusivity $D$ was measured for the temperature range of $50-800^{\circ} \mathrm{C}$ by a laser flash method (LFA 457 , Netzsch). The specific heat was calculated using the rule of mixtures [43].

The obtained thermal conductivity and thermal expansion coefficient values were shown in Fig. 12 for the produced graded material in section.

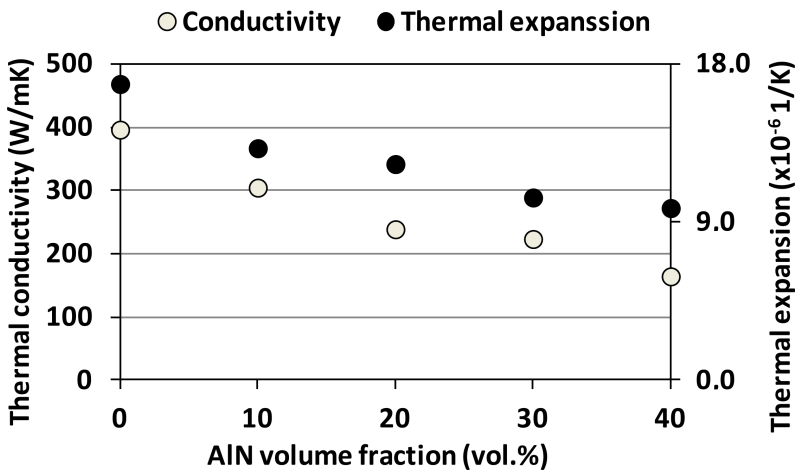

Fig. 12. Thermal conductivity and linear expansion coefficient changes for $\mathrm{Cu}$-AlN composite materials

When compared with the results obtained for pure copper, the performed measurements showed a decrease in both thermal expansion coefficient and thermal conductivity of particular components of the graded material. According to theoretical calculations (using the rule of mixtures), the thermal expansion coefficient for composite materials in the $\mathrm{Cu} / 10$ $40 \%$ AlN range at ambient temperature should be around 11$15 \times 10^{-6} 1 / \mathrm{K}$. Therefore, the obtained values were a bit higher than expected. These differences can result from the presence of pores in the structure of particular layers of the graded material and the fact that they have not been taken into ac- 


\section{Metal-ceramic functionally graded materials - manufacturing, characterization, application}

count in calculations. From the point of view of substrate's fitting to the semiconducting element it is advantageous, but decreased thermal conductivity caused by the presence of porosity should be treated as a negative phenomenon. Taking into account theoretical conductivity values $\left(\lambda_{C u}=396 \mathrm{~W} / \mathrm{mK}\right.$ and $\lambda_{A l N}=150 \mathrm{~W} / \mathrm{mK}$ ) and porosity in the layer structure of the graded material (4-5\% maximum), the obtained results are promising and perfecting technological conditions should lead to the reduction of porosity to a degree enabling the application of the developed materials.

\section{Conclusions}

In modern engineered structures pure metals or alloys are less frequently used as a result of higher requirements and complexity of the applied materials. In order to fulfill the expectations of constructors, new material combinations are designed based on metals, ceramic materials and plastics. Composites belong to a new class of advanced materials allowing to join different components and obtain unprecedented properties. In the age of miniaturized electronic components, requiring both removal and dissipation of high-power heat flux, the weight of load-bearing and automotive structures has to be decreased for economic and ecological reasons. Materials with a composition gradient belong to a particularly interesting group based on composites, offering the change of properties when altering one of the dimensions.

In the case of functionally graded materials disadvantageous sharp interfaces existing in a composite material are eliminated. These sharp interfaces are replaced with a gradient interface, which guarantees smooth transition from one material to another [44]. As it was stated in the introduction the possible areas of application of FGMs include aerospace, automobile industry, defense, energy, optoelectronics, medicine, sport, etc.

The overview presented by the authors shows only a few selected potential applications of FGMs to industrial practice. The proposed solutions can be treated as a contribution to knowledge about graded materials and its dissemination; however, the subject area still requires further advanced research into both characterization of their properties and their behavior under conditions resembling operational conditions. It has to be highlighted that at present the production cost of graded materials is relatively high but due to a tremendous interest in the subject matter expressed worldwide as well as higher level of knowledge about these materials, it should be reduced in the long term. As a result, graded materials, until now referred to as materials of the future, are expected to become 21 st century materials.

Acknowledgements. The results presented in this paper have been obtained within the project "KomCerMet" (contract No. POIG.01.03.01-14-013/08-00 with the Polish Ministry of Science and Higher Education) within the framework of the Operational Programme for Innovative Economy 2007-2013 and within the project No N508 308633 financed by the Polish Ministry of Science and Higher Education.

\section{REFERENCES}

[1] M. Koizumi, "The concept of FGM", Ceramic Transactions 34, 3-11 (1993).

[2] Y.M. Shabana and N. Noda, "Thermo-elasto-plastic stresses in functionally graded materials subjected to thermal loading taking residual stresses of the fabrication process into consideration", Composites Part B 32, 111-121 (2001).

[3] B. Kieback, A. Neubrand, and H. Riedel, "Processing techniques for functionally graded materials", Materials Science and Engineering A362, 81-105, (2003).

[4] R. Zybala and K.T. Wojciechowski, "Anisotropy analysis of thermoelectric properties of $\mathrm{Bi} 2 \mathrm{Te} 2.9 \mathrm{Se} 0.1$ prepared by the SPS method", Proc. 9th Eur. Conf. on Thermoelectrics (ECT), AIP Conf. Proc. 1, 393-396 (2011).

[5] M. Barlak, "Creep resistant gradient $\mathrm{Al}_{2} \mathrm{O}_{3}-\mathrm{Cr}$ composites", Composites - Theory and Practice 1, 105-113 (2000).

[6] M.A. Uusitalo, P.M.J. Vuoristo, and T.A. Mantyla,'High temperature corrosion of coatings and boiler steels in reducing chlorine-containing atmosphere", Surface and Coatings Technology 161 (2-3), 275-285 (2002).

[7] M.F. Morks and C.C. Berndt, "Corrosion and oxidation properties of $\mathrm{NiCr}$ coatings sprayed in presence of gas shroud system", Applied Surface Science 256, 4322-4327 (2010).

[8] J. Zimmerman, Z.Lindemann, D.Golanski, T. Chmielewski, and W. Wlosinski, "Modeling residual stresses generated in Ti coatings thermally sprayed on $\mathrm{Al}_{2} \mathrm{O}_{3}$ substrates", Bull. Pol. Ac.: Tech. 61 (2), 515-525 (2013).

[9] L. Feng and J. Junhong, "Tribological properties and wear mechanisms of $\mathrm{NiCr}_{-} \mathrm{Al}_{2} \mathrm{O}_{3}-\mathrm{SrSO}_{4}-\mathrm{Ag}$ self-lubricating composites at elevated temperatures", Tribology Letters 49 (1), 281-290 (2013).

[10] M. Chmielewski, K. Pietrzak, Processing, microstructure and mechanical properties of $\mathrm{Al}_{2} \mathrm{O}_{3}-\mathrm{Cr}$ nanocomposites, J. Eur Ceramic Society 27 (2-3), 1273-1279 (2007).

[11] W. Węglewski, M. Basista, A. Manescu, M. Chmielewski, K. Pietrzak, and Th. Schubert, "Effect of grain size on thermal residual stresses and damage in sintered chromium-alumina composites: measurement and modeling", Composites Part B 67, 119-124 (2014).

[12] M. Chmielewski, K. Pietrzak, A. Strojny-Nedza, B. Dubiel, and A. Czyrska-Filemonowicz, "Effect of rhenium addition on the strengthening of chromium-alumina composite materials", Int. J. Materials Research 105 (2), 200-207 (2014).

[13] P. Caron and T. Khan, "Evolution of Ni-based superalloys for single crystal gas turbine blade applications", Aerospace Science and Technology 3, 513-523 (1999).

[14] W. Wlosinski and T. Chmielewski, "Plasma-hardfaced chromium protective coatings-effect of ceramic reinforcement on their wettability by glass", Contributions of Surface Engineering to Modern Manufacturing and Remanufacturing 1, 48-53 (2002).

[15] M.Y. Zhou, J.T. Xi, and J.Q. Yan, "Modeling and processing of functionally graded materials for rapid prototyping", $J$. Materials Processing Technology 146 (3), 396-402 (2004).

[16] M. Szafran, K. Konopka, E. Bobryk, and J.K. Kurzydlowski, "Ceramic matrix composites with gradient concentration of metal particles", J. Eur. Ceramic Society 27 (2-3), 651-654 (2007).

[17] W. Zorawski, R. Chatys, N. Radek, and J. BorowieckaJamrozek, "Plasma-sprayed composite coatings with reduced friction coefficient", Surface and Coatings Technology 202, 4578-4582 (2008). 


\section{Chmielewski and K. Pietrzak}

[18] C. Pierlot, L. Pawlowski, M. Bigan, and P. Chagnon, "Design of experiments in thermal spraying: a review", Surface and Coatings Technology 202, 4483-4490 (2008).

[19] T. Chmielewski, D. Golanski, and W. Wlosinski, "Metallization of ceramic materials based on the kinetic energy of detonation waves", Bul. Pol. Ac.: Tech. 63 (2), 449-456 (2015).

[20] K. Pietrzak, W. Olesinska, D. Kalinski, and A. StrojnyNedza, "The relationship between microstructure and mechanical properties of directly bonded copper-alumina ceramics joints", Bul. Pol. Ac.: Tech. 62 (1), 23-32 (2014).

[21] K. Pietrzak, D. Kaliński, and M. Chmielewski, "Interlayer of $\mathrm{Al}_{2} \mathrm{O}_{3}-\mathrm{Cr}$ functionally graded material for reduction of thermal stresses in alumina - heat resisting steel joints", J. Eur. Ceramic Society 27 (2-3), 1281-1286 (2007).

[22] L. Salbut, M. Kujawinska, M. Jozwik, and D. Golanski," Investigation of ceramic-to-metal joint properties by hybrid moire interferometry/FEM analysis", Interferometry '99: Applications, Book Series: Proc. Society of Photo-Optical Instrumentation Engineers (SPIE) 3745, 298-306 (1999).

[23] H.Y. Yu, S. Sanday, and B. Rath, "Residual stresses in ceramicinterlayer-metal joints", J. American Ceramic Society 76 (7), 1661-1664 (1993).

[24] M. Chmielewski, D. Kaliński, and K. Pietrzak, "Thermal residual stresses in alumina - heat resisting steel joints with an interlayer of $\mathrm{Al}_{2} \mathrm{O}_{3}-\mathrm{Cr}$ functionally graded material. Part I. Interlayer selection", Advances in Manufacturing Science and Technology 28 (3), 99-111 (2004).

[25] M. Chmielewski, D. Kaliński, and K. Pietrzak, "Thermal residual stresses in alumina - heat resisting steel joints with an interlayer of $\mathrm{Al}_{2} \mathrm{O}_{3}-\mathrm{Cr}$ functionally graded material. Part II. Optimization of a functionally graded material for reduction of thermal stresses", Advances in Manufacturing Science and Technology 28 (4), 68-77 (2004).

[26] A.M. Glaeser, "The use of transient FGM interlayers for joining advanced ceramics", Composites Part B 28 (1-2), 71-84 (1997).

[27] C.S. Lee, X.F. Zhang, and G. Thomas, "Novel joining of dissimilar ceramics in the $\mathrm{Si}_{3} \mathrm{~N}_{4}-\mathrm{Al}_{2} \mathrm{O}_{3}$ system using polytypoid functional gradients", Acta Materialia. 49 (18), 3775-3780 (2001).

[28] T. Weber and J. Aktaa, "Numerical assessment of functionally graded tungsten/steel joints for divertor applications", Fusion Engineering and Design 86 (2-3), 220-226 (2011).

[29] Micro and Nanocrystalline Functionally Graded Materials for Transport Applications (MATRANS), project financed within European Union's Seventh Framework Programme (FP7/20072013) under Grant Agreement No. 228869

[30] S. Nosewicz, J. Rojek, S. Mackiewicz, M. Chmielewski, K. Pietrzak, and B. Romelczyk, "The influence of hot pressing conditions on mechanical properties of nickel aluminide/alumina composite", J. Composite Materials 48 (29), 3577-3589 (2014).
[31] R. Darolia, "Ductility and fracture toughness issues related to implementation of NiAl for gas turbine applications", Intermetallics 8, 1321-1327 (2000).

[32] M. Chmielewski, S. Nosewicz, K. Pietrzak, J. Rojek, A. Strojny-Nędza, S. Mackiewicz, and J. Dutkiewicz, "Sintering behaviour and mechanical properties of $\mathrm{NiAl}, \mathrm{Al}_{2} \mathrm{O}_{3}$, and $\mathrm{NiAl}-\mathrm{Al}_{2} \mathrm{O}_{3}$ composites", J. Materials Engineering and Performance 23, 3875-3886 (2014).

[33] D. Kaliński, M. Chmielewski, K. Pietrzak, and K. Choręgiewicz, "An influence of mechanical mixing and hotpressing on properties of $\mathrm{NiAl} / \mathrm{Al}_{2} \mathrm{O}_{3}$ composite", Archives of Metallurgy and Materials 57 (3) 694-702 (2012).

[34] D. Tingaud and F. Nardou, "Influence of non-reactive particles on the microstructure of $\mathrm{NiAl}$ and $\mathrm{NiAl}-\mathrm{ZrO}_{2}$ process by thermal explosion", Intermetallics 16, 732-737 (2008).

[35] W.H. Tuan, Toughening alumina with nickel aluminide inclusions, J. Eur. Ceramic Society 20, 895-899 (2000).

[36] J. Cook, C.C. Evans, J.E. Gordon, and D.M. Marsh, "Mechanism for control of crack propagation in all-brittle systems", Proc. Royal Society of London Series A-Mathematical and Physical Sciences 1, 282 (1390), 508-520 (1964).

[37] P. Mankowski, A. Dominiak, R. Domanski, M.J. Kruszewski, and L. Ciupinski, "Thermal conductivity enhancement of copper-diamond composites by sintering with chromium additive", J. Thermal Analysis and Calorimetry 116 (2), 881-885 (2014).

[38] K. Jagannadham, "Orientation dependence of thermal conductivity in copper-graphene composites", J. Applied Physics 110, 074901 (2011).

[39] Th. Schubert, B. Trindade, T. Weissgaerber, and B. Kieback, "Interfacial design of Cu-based composites prepared by powder metallurgy for heat sink applications", Materials Science and Engineering A475 (1-2), 39-44 (2008).

[40] J. Tian and K. Shobu, "Hot-pressed AlN-Cu metal matrix composites and their thermal properties", J. Materials Science 39, 1309-1313, (2004).

[41] A. Strojny-Nedza and K. Pietrzak, "Processing, microstructure and properties of different method obtained $\mathrm{Cu}-\mathrm{Al}_{2} \mathrm{O}_{3}$ composites", Archives of Metallurgy and Materials 59 (4), 1307-1312 (2014).

[42] M. Chmielewski, D. Kaliński, K. Pietrzak, and W. Włosiński, "Relationship between mixing conditions and properties of sintered 20AlN/80Cu composite materials", Archives of Metallurgy and Materials 55 (2), 579-585 (2010).

[43] M. Chmielewski and W. Weglewski, "Comparison of experimental and modelling results of thermal properties in $\mathrm{Cu}-\mathrm{AlN}$ composite materials", Bull. Pol. Ac.: Tech. 61 (2), 507-514 (2013).

[44] R.M. Mahamood and E.T. Akinlabi, "Functionally graded material: an overview", Proc. World Cong. Engineering 1, CDROM (2012). 